\title{
ALIMENTO ORGÂNICO, SAÚDE E MEIO AMBIENTE: OS DESAFIOS DA ALIMENTAÇÃO NATURAL.
}

\author{
Alba Regina Azevedo Arana ${ }^{1}$
}

\section{Anderson Murilo de Lima}

\begin{abstract}
RESUMO: Esta pesquisa teve por objetivo discutir a alimentação orgânica e a alimentação saudável apresentando os benefícios para o meio ambiente e a saúde humana. Em contraposição faz uma abordagem sobre a alimentação advinda da agricultura convencional calcada na forte utilização de agroquímicos e seus impactos na saúde do homem, sendo tema de relevância para o novo contexto agrícola dos modos de produção que respeita as leis da natureza abordando a relação alimentação x saúde. Os dados foram obtidos por meio de pesquisas já realizadas confrontadas com informações de pesquisa bibliográfica. Pode-se observar o importante papel desempenhado pela participação das instituições públicas, comunidades locais e setores econômicos na implementação de projetos e ações para uma alimentação saudavel. Contudo, as estatísticas apresentam a larga utilização de agroquímicos e seus efeitos na saúde humana. O principal resultado do PARA - Programa de Análise de Resíduos de Agrotóxicos em Alimentos é a evidência da necessidade de desenvolver um planejamento estratégico que possa reduzir os efeitos nocivos do uso dos agrotóxicos, tanto para a saúde humana como para o meio ambiente
\end{abstract}

Palavras-chave: Trabalho. Saúde. Meio ambiente.

\footnotetext{
${ }^{1}$ (alba@unoeste.br) Doutora em Geografia; Docente do Mestrado em Meio Ambiente e Desenvolvimento Regional da Unoeste.

2 (andmurilo@hotmail.com) Especialista em Comércio Exterior e Negócios Internacionais; Mestrado em Meio Ambiente Desenvolvimento Regional da Unoeste.
} 


\section{1- INTRODUÇÃO}

Há muitos anos a sociedade utilizava um modelo de desenvolvimento baseado em economia, considerando que as fontes de matérias-primas seriam inesgotáveis e que 0 planeta assimilaria os resíduos indefinidamente, além de que a geração de poluentes seria inevitável na produção de bens/serviços e que a tecnologia seria capaz de resolver todos os problemas surgidos a partir da aplicação desse modelo.

No inicio da década de 1970, como uma resposta à preocupação da humanidade, diante da crise ambiental e social que se abateu sobre o mundo desde a segunda metade do século passado, foi possível perceber que o planeta não seria capaz de absorver todo o rejeito oriundo das atividades do homem, nem tão pouco as tecnologias, apesar de suas inovações plausíveis, solucionariam todos os problemas, visto que o planeta é um sistema fechado, limitado e esgotável, não podendo sustentar indefinidamente o crescimento da sociedade humana consumindo bens e serviços infinitamente.

Segundo Santos (apud CAVALCANTI, 2003), o tipo de desenvolvimento que o mundo experimentou nos últimos duzentos anos, especialmente depois da Segunda Guerra Mundial, é insustentável. Assim sendo, são visíveis os impactos resultantes desse modelo, nos quais cerca de metade dos rios estão seriamente contaminados, graves restrições no abastecimento de água, grande proliferação de doenças decorrentes do uso de águas contaminadas. Além disso, as elevadas concentrações de CO2 na atmosfera, efeito estufa, aumento do "buraco" na camada de ozônio, degradação do solo, extinção das espécies devido à degradação do habitat, mudanças no clima, elevação de temperatura dos mares, dentre outros.

A partir dos impactos supracitados, surge a necessidade de um modelo de sociedade que almeje a minimização de tais problemas, uma sociedade que apenas não cresça, mas se desenvolva sustentavelmente. Para isso, faz-se necessário o equilíbrio entre muitas dimensões, quais sejam: político, econômico, social, institucional, cultural, saúde e ambiental, contribuindo assim para o alcance do desenvolvimento sustentável.

Dentre as variáveis que mantém relação com a temática do desenvolvimento sustentável, destaca-se o contexto da agricultura onde o homem tem relação direta com os recursos naturais. 
A agricultura tem a missão de prover o mundo com os diversos tipos de alimentos, mas depende de recursos naturais vitais, como o solo, a água, a luz do sol, etc., tendo como desafio a produção de grandes quantidades como exemplo cereais, frutas, legumes, a fim de satisfazer a demanda. Assim, é visível a importância de se alcançar a sustentabilidade na agricultura, visto que as atividades agrícolas responsáveis pela obtenção de alimento, sempre exerceram grandes pressões sobre o meio ambiente. O uso inadequado dos recursos naturais tem promovido intensa degradação ambiental, a partir da destruição de hábitat e de espécies potencialmente úteis para a sobrevivência do planeta, o que deve ser discutido no intuito de encontrar possíveis caminhos para reverter e/ou minorar tal impasse.

Desta forma, é preciso ações e atividades que promovam novos estilos de desenvolvimento para a agricultura, que respeitem as condições específicas de cada agroecossistema, assim como a preservação da biodiversidade e a diversidade cultural, de forma a assegurar que gerações futuras possam usufruir dos "mesmos" recursos existentes no planeta. Deste modo, diferentes princípios agronômicos, ecológicos e socioeconômicos foram fundamentais para nortear uma concepção multidisciplinar, assim como um novo modelo de desenvolvimento e, por conseguinte, a construção da sustentabilidade na agricultura.

Nesse contexto, o novo modelo agrícola, que surge em meio às preocupações ambientais, traz a busca por uma agricultura limpa e sustentável que procura inserir esse novo paradigma, e traz como alternativa a agroecologia, que fornece uma estrutura metodológica de trabalho trazendo o respeito às leis naturais e a compreensão mais profunda da natureza e dos agroecossistemas como, também, dos princípios segundo os quais estão calcados. Trata-se da integração de princípios agronômicos, ecológicos e socioeconômicos à compreensão e avaliação do efeito das tecnologias sobre os sistemas agrícolas e à sociedade como um todo, assim como tenta incorporar, de forma sistêmica, as três dimensões de sustentabilidade: um sistema agrícola economicamente viável, socialmente justo e ecologicamente sustentável.

Este trabalho visa discutir sobre a alimentação orgânica e em especial sobre a alimentação saudável apresentando os benefícios para o meio ambiente e a saúde humana. Em contraposição faz uma abordagem sobre a alimentação advinda da 
agricultura convencional calcada na forte utilização de agroquímicos e seus impactos na saúde do homem, sendo tema de relevância para o novo contexto agrícola dos modos de produção que respeita as leis da natureza abordando a relação alimentação x saúde.

\section{2- ALIMENTAÇÃO HUMANA X SAÚDE: BREVE CONTEXTO HISTÓRICO.}

Devido às novas necessidades advindas da plena expansão nos domínios do homem moderno, especificadamente, a intensificação dos conflitos agroambientais que se deu a parir da segunda metade do século $X X$ oriundo principalmente da utilização de agroquímicos na agricultura o que, levou à situação atual de altos índices de resíduos em produtos hortifrutigranjeiros, assim como a utilização de promotores de crescimento e antibióticos na agropecuária. Não só a escala de produção tornou-se significante, mas principalmente pelos recursos adquiridos através do retorno financeiro proporcionados pelas atividades conduzidas de modo racional. Paralelamente a esta evolução moderna, pesquisas começaram a evoluir sobre os efeitos nos organismos de animais e de humanos.

Dentro do processo evolutivo muitas teorias e fatos sobre alimentação e saúde surgiram , assim como em outras áreas da ciência, sendo uns aceitos e comprovados, outros mantidos por gerações e outros contestados e provados sua ineficiência acabando por perder sua credibilidade dentro da comunidade científica e conseqüentemente pela sociedade.

Clarividências se fazem presentes ao observarmos que dentro da lei da natureza o hábito de se alimentar é inerente ao homem, assim como todos os demais seres, podendo hoje tanto manter sua saúde como destruí-la dependendo do seu estilo de vida.

Okada (1950, p. 41), ao tratar sobre a verdadeira saúde do homem diz:

Para explanar sobre o assunto, devo dizer inicialmente que a verdade, em matéria de saúde, está na adaptação e no respeito à natureza. Essa é a condição fundamental [...]. Mas o que descobrimos ao examinar o corpo humano em estado anormal? Em primeiro lugar ressalta que ele está em desacordo com a Natureza. 
Dentro dos ciclos evolutivos da humanidade, aliado ao contexto traçado pela alimentação, mas, historicamente de maneira muito mais recente, descortinou-se o caminho da nutrição.

Foi no século $X X$ que se ampliou as investigações no campo da nutrição. Segundo Leonard (2012), a evolução das investigações sobre as necessidades nutricionais se deram:

\begin{abstract}
[...] Investigações relevantes começaram a ganhar espaço a partir de 1985, quando S. Boyd Eaton e Melvin J. Konner, da Emory University, publicaram um artigo no New England Journal of Medicine intitulado "Nutrição Paleolítica". Eles argumentam que a prevalência de muitas doenças crônicas nas sociedades modernas - entre elas obesidade, hipertensão, doenças coronarianas e diabetes - seriam o resultado de uma incompatibilidade entre padrões dietéticos modernos e o tipo de dieta que nossa espécie desenvolveu para se alimentar como caçadores-coletores préhistóricos.
\end{abstract}

Trazendo uma nova visão antes mesmo de o desenvolvimento do campo da nutrição ter ganhado espaço na década de 1980, Okada (1947, p. 152), afirmou que "o erro fundamental da dietética moderna é basear suas pesquisas em apenas um dos dois aspectos da nutrição". Ela discute o alimento como objeto principal dessas pesquisas, negligenciando a parte que se refere às funções orgânicas.

Okada (1950, p. 155), em seu artigo intitulado "A Comédia da Nutrição", diz:

\begin{abstract}
Não seria preciso explicar, a essas alturas, que o alimento serve para manter a vida; na interpretação deste aspecto, porém, há uma grande diferença entre a teoria atual e a realidade. Quando o homem ingere um alimento [...]. As partes necessárias são absorvidas, enquanto o resto é eliminado. Até chegar a esse processo, entram em ação diversos órgãos, como o fígado, a vesícula biliar, os rins, o pâncreas e outros, que extraem, produzem e distribuem os nutrientes necessários ao sangue, músculos, ossos, pele, cabelos, dentes, unhas, etc. Assim, é realizada incessantemente a atividade de manutenção da vida. Trata-se de uma misteriosa obra da criação, impossível de ser expressa por meio de palavras. É esse o estado normal da Natureza.
\end{abstract}

O Brasil não fugiu a esta modernização do agronegócio em todos os sentidos tanto a nível animal como da produção agrícola. A Agência Nacional de Vigilância Sanitária ANVISA (2209) publicou: - "um dado preocupa as autoridades sanitárias nacionais. Em 2008, o Brasil assumiu o posto de maior consumidor de agrotóxicos em todo mundo, 
posição antes ocupada pelos Estados Unidos. Só o mercado de agrotóxicos movimentou mais de US\$ 7 bilhões".

As estatísticas apresentam a larga utilização de agroquímicos e seus efeitos na saúde humana, o Governo Federal tem traçado programas específicos nos últimos anos através das pastas ministeriais, como o "Plano Nacional de Controle de Resíduos e Contaminantes - PNCRC" que é um programa federal do Ministério da Agricultura MAPA, de inspeção e fiscalização de alimentos, baseado em análise de risco, que visa verificar a presença de resíduos de substâncias químicas potencialmente nocivas à saúde do consumidor, como resíduos de medicamentos veterinários, de agrotóxicos ou afins, de contaminantes ambientais (ex: aflatoxinas) e de contaminantes inorgânicos (metais pesados).

A Agência Nacional de Vigilância Sanitária - ANVISA instituiu o Programa de Análise de Resíduos de Agrotóxicos em Alimentos (PARA) tendo iniciado em 2001 com o objetivo de avaliar continuamente os níveis de resíduos de agrotóxicos nos alimentos in natura que chegam à mesa do consumidor. A ANVISA coordena o programa em conjunto com as vigilâncias sanitárias dos estados participantes, que realizam os procedimentos de coleta dos alimentos nos supermercados e de envio aos laboratórios para análise (ANVISA, 2010).

Segundo a ANVISA (2012), o PARA integra medidas de controle pós-registro que têm promovido diversas mudanças na organização dos serviços de saúde para prevenção de agravos relacionados aos agrotóxicos. Seus resultados levantam discussões sobre o direito à informação. Também têm fomentado a articulação, no âmbito federal e estadual, entre os diferentes atores envolvidos na produção, consumo e controle de agrotóxicos, assim como publicações e pesquisas sobre o impacto dos agrotóxicos na saúde. Suas atividades têm por objetivos principais a promoção da saúde através do consumo de alimentos de qualidade e a prevenção das doenças crônicas não transmissíveis (DCNT) secundárias à ingestão cotidiana de quantidades perigosas de agrotóxicos.

No período de 2001 a 2004 foram estudadas cerca de 4 mil amostras de alimentos in natura coletadas em 12 Estados brasileiros, inclusive no Rio. Destas 2032 possuíam algum tipo de resíduo, sendo que algumas apresentavam resíduos de mais de um produto, 
nos levando ao número de 3271, resíduos detectados. Destes, 83,4\% dizia respeito a produtos irregulares, ou não autorizados e 16,6\% das amostras encontravam-se com níveis acima do tolerado pela legislação, (Pimenta, 2006).

As amostras foram encaminhadas preferencialmente para os LACEN e, desde 2001, o método analítico empregado é o de "multiresíduos". Trata-se da mais reconhecida e utilizada tecnologia para monitoramento de resíduos de agrotóxicos em alimentos, adotada por países como Alemanha, Austrália, Canadá, Estados Unidos e Holanda.

Segundo a ANVISA (2011), ainda, no processo de divulgação busca-se informar os consumidores sobre os cuidados a adotar para reduzir os resíduos de agrotóxicos nos alimentos: a escolha de alimentos sem agrotóxicos ou de procedência confiável no que se refere à adoção de boas práticas agrícolas.

De acordo com o plano de amostragem estabelecido para 2010, foi prevista a coleta de seis amostras de cultura e por Unidade Federativa (UF), gerando um total de 2488 amostras (ANVISA, 2010). Para este trabalho, foram escolhidas cinco culturas (pimentão, morango, pepino, alface e couve) identificadas com índice de ingredientes ativos não autorizados (NA) que foram analisadas pela ANVISA referente aos anos de 2009 e 2010 dentre as 20 culturas analisadas nos 25 estados da federação em 2009 e 26 para o ano de 2010, para análise comparativa da evolução ou involução da utilização de agroquímicos.

Segundo a ANVISA (2010), a coleta dos alimentos foram realizadas em supermercados tendo como objetivo verificar se os alimentos comercializados possuem qualidade de acordo com as autorizações de uso dos agrotóxicos e os limites de resíduos de agrotóxicos estabelecidos pela ANVISA.

A tabela 01 descreve os resultados do comparativo realizado 
Tabela 01: Número de amostras analisadas por cultura e resultados insatisfatórios.

PARA, 2009 e 2010

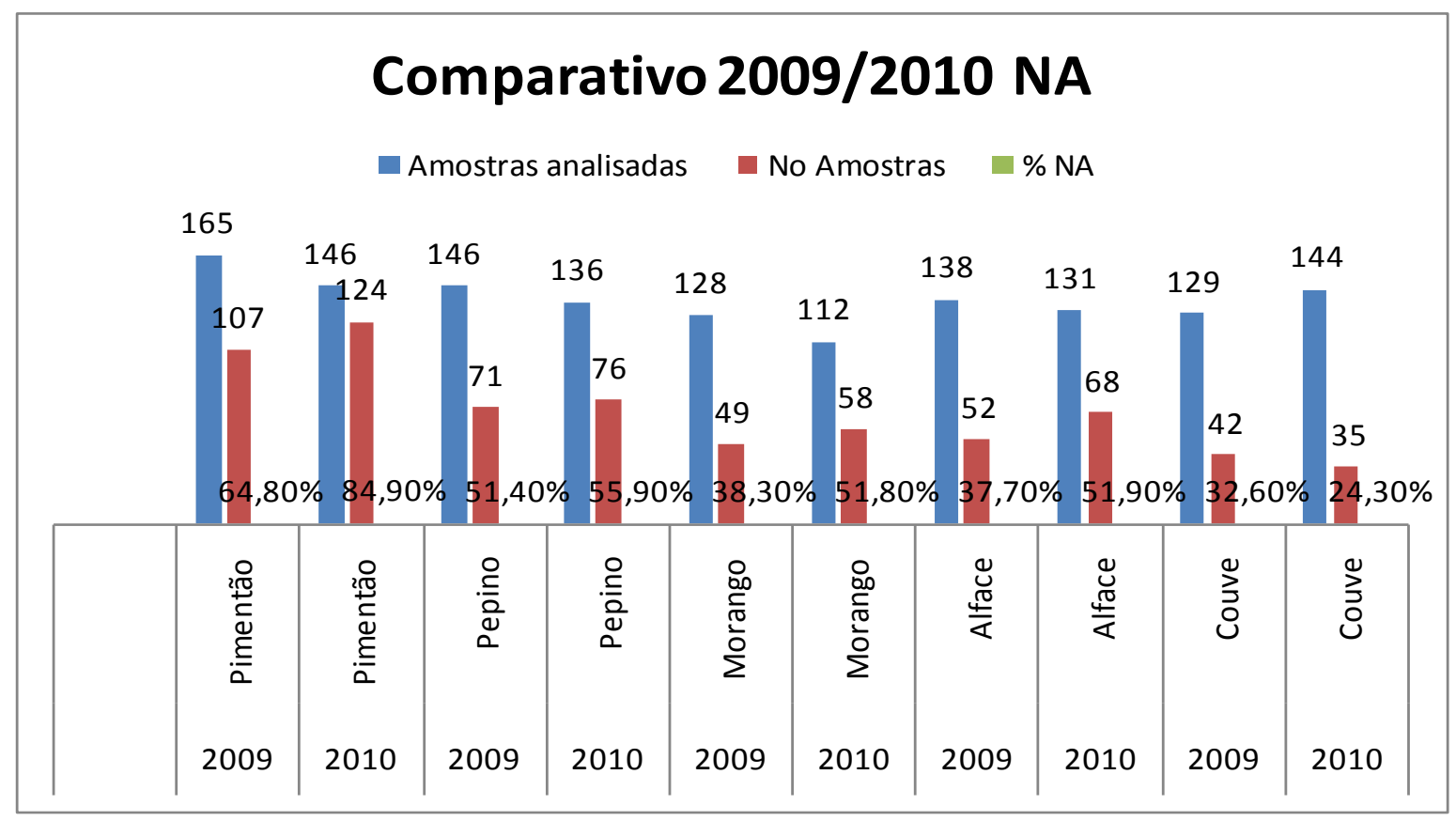

Observa-se na tabela 01 que, para os anos de 2009 e 2010 para as culturas do pimentão, pepino, morango e alface os índices de ingredientes ativos não autorizados apresentaram um aumento na porcentagem onde o pimentão teve um aumento de $20,10 \%$, o pepino $4,50 \%$, o morango $13,50 \%$ e a alface $14,20 \%$.

A couve dentro da análise foi o único produto que apresentou um decréscimo na utilização de ingredientes não autorizados na ordem de -8,30\%.

Para os resultados demonstrados na tabela 01, segundo a ANVISA (2011), os resultados insatisfatórios é devido à utilização de agrotóxicos não autorizados e que resultam em dois tipos de irregularidades:

- seja porque foi aplicado um agrotóxico não autorizado para aquela cultura, mas cujo IA está registrado no Brasil e com uso permitido para outras culturas;

- seja porque foi aplicado um agrotóxico banido do Brasil ou que nunca teve registro no país, logo, sem uso permitido em nenhuma cultura. 
O principal resultado do PARA é a evidência da necessidade de desenvolver um planejamento estratégico que possa reduzir os efeitos nocivos do uso dos agrotóxicos, tanto para a saúde humana como para o meio ambiente.

Ao órgão responsável pela saúde, cabe a ampliação das ações de monitoramento de resíduos, a fiscalização da qualidade e a reavaliação toxicológica dos agrotóxicos, com a finalidade de reduzir a exposição da população àquelas substâncias de maior perigo. Compete-lhe, ainda, a definição de mecanismos eficazes para registro de produtos de baixa toxicidade, bem como apoiar políticas e projetos voltados para a transição do modelo agrícola atual para a produção agroecológica de alimentos, respeitando o meio ambiente.

Em relação aos consumidores, o PARA preconiza a opção por alimentos de origem identificada, o que pode contribuir para o comprometimento dos produtores em relação à qualidade dos seus produtos e à adoção de Boas Práticas Agrícolas. Desta forma, eles colaboram e fomentam as iniciativas dos programas estaduais e das redes varejistas de garantir a rastreabilidade e o controle da qualidade dos alimentos. Também é importante lembrar que os agrotóxicos pulverizados ou distribuídos sobre as culturas agrícolas e o solo têm a capacidade de penetrar no interior de folhas e polpas, e que os procedimentos de lavagem e retirada de cascas e folhas externas das mesmas favorecem a redução dos resíduos de agrotóxicos, limpando a superfície dos alimentos, mas sendo incapazes de eliminar aqueles contidos em suas partes internas. Da mesma forma, a higienização dos alimentos com solução de hipoclorito de sódio tem o objetivo de diminuir os riscos microbiológicos, mas não de eliminar agrotóxicos ANVISA (2011).

No tabela 03 relacionamos os problemas e/ou agravos à saúde causados pelos Ingredientes Ativos de agrotóxicos em reavaliação/ou já banidos com as respectivas restrições ao uso nos vários países do mundo, Carneiro, F. et al (2012). 
Tabela 03. Efeitos tóxicos dos ingredientes ativos de agrotóxicos banidos ou em reavaliação com as respectivas restrições ao uso no mundo.

\begin{tabular}{|c|l|l|}
\hline Agrotóxicos & \multicolumn{1}{|c|}{ Problemas relacionados } & \multicolumn{1}{c|}{ Proibido ou restrito } \\
\hline Abamectina & $\begin{array}{l}\text { Toxicidade aguda e suspeita } \\
\text { de toxicidade reprodutiva do } \\
\text { IA e de seus metabólitos }\end{array}$ & $\begin{array}{l}\text { Comunidade Européia - } \\
\text { proibido }\end{array}$ \\
\hline Cihexatina & $\begin{array}{l}\text { Alta toxicidade aguda, } \\
\text { suspeita de carcinogenicidade } \\
\text { para seres humanos, } \\
\text { toxicidade reprodutiva e } \\
\text { neurotoxicidade }\end{array}$ & $\begin{array}{l}\text { Comunidade Européia, } \\
\text { Japão, Estados Unidos, } \\
\text { Canadá- proíbido. Uso } \\
\text { exclusivo para citrus no } \\
\text { Brasil , 2010 }\end{array}$ \\
\hline \multirow{2}{*}{ Endossulfam } & $\begin{array}{l}\text { Alta toxicidade aguda, } \\
\text { suspeita de desregulação } \\
\text { endócrina e toxicidade } \\
\text { reprodutiva. }\end{array}$ & $\begin{array}{l}\text { Comunidade Européia- } \\
\text { proíbido, Índia (autorizada } \\
\text { só a produção) A ser } \\
\text { proibido no Brasil a partir } \\
\text { julho de 2013 }\end{array}$ \\
\hline
\end{tabular}

Fonte: Adaptado da ANVISA, 2008; ANVISA \& UFPR, 2012.

Para os dados apresentados na tabela 03 pela Carneiro et al (2012, p. 35), relatam:

Embora brevemente aqui reunidas, as evidências já disponíveis de danos dos agrotóxicos à saúde alertam para a gravidade da problemática, na medida em que dialogam com os grupos de agravos prevalentes no perfil de morbi-mortalidade do país. Entretanto, este conhecimento nos permite visualizar apenas a ponta do iceberg, tendo em vista que a massiva maioria dos estudos parte de análises em animais ou in vitro, e que tais estudos analisam a exposição a um único ingrediente ativo, situação rara no cotidiano das pessoas, que podem ingerir, num só alimento, dezenas de ingredientes ativos. Como se verá no item sobre os desafios ao conhecimento, muito pouco se sabe sobre os efeitos da exposição múltipla e a baixas doses.

Vê-se conforme apresentado que se continuar com 0 modo de produção convencional, o homem não poderá se alimentar num futuro próximo.

\section{3- AGRICULTURA SAUDÁVEL: OS DESAFIOS PARA UMA ALIMENTAÇÃO NATURAL}


A história demonstra a passagem de vários precursores das mais variadas correntes literárias, econômicas, científicas, sociais e etc., sendo que no tocante a agricultura e alimentação no século XX surgiram algumas correntes filosóficas abordando novos conceitos e teorias a respeito da produção limpa, verde, que respeita a grande natureza.

Khatounian (2001, p. 25) sobre o desenvolvimento dos modos de produção teceu:

Assim, o modo de produção baseado em insumos químicos, primeiro fertilizantes, depois biocidas, alcançou todos os quadrantes geográficos do planeta, em maior ou menor intensidade, o mesmo ocorrendo com a poluição industrial. Disso resultou que os problemas trazidos pela poluição industrial e pela agricultura mumificada igualmente se generalizaram pelo mundo. Resultou também num grande número de reações, buscando o desenvolvimento de modos de produção mais naturais ou ao menos de menor impacto no ambiente.

Na construção da linha do tempo houve três precursores destes novos conceitos e teoria onde se destacam três movimentos: biodinâmica, orgânica e natural.

Segundo Khatounian (2001, p. 25) sobre a Biodinâmica considera:

A Alemanha, berço da química agrícola, foi também o berço da mais antiga reação, cristalizada em 1924, sob a denominação de Biologische Dynamische Landwirtschaft, mais tarde disseminada como biodinâmica. Esse movimento teve como figura central o filósofo Rudolf Steiner [...]. Esse método preconizava a moderna abordagem sistêmica, entendendo a propriedade como um organismo e destacava a presença de bovinos como um dos elementos centrais para o equilíbrio do sistema.

Khatounian (2001, p. 26), sobre a agricultura orgânica diz:

Na Inglaterra surge a corrente denominada Organic Agriculture, que mais tarde se dissemina pelos Estados Unidos com o mesmo nome. Sua figura central foi o agrônomo Albert Howard, com extensa experiência na Índia, então colônia britânica. Howard observava que a adubação química produzia excelentes resultados nos primeiros anos, mas depois os rendimentos caíam drasticamente, enquanto os métodos tradicionais dos camponeses indianos resultavam em rendimentos menores, mas constantes.

Sobre o terceiro movimento, o da Agricultura Natural, Khatounian (2001, p. 26), descreve:

No Japão, nas décadas de 1930 e 1940, desenvolveu-se um movimento de caráter filosófico-religioso, cuja figura central foi Mokiti Okada [...]. Um dos pilares desse 
movimento foi o método agrícola denominado Shizen No Hou, traduzido como o "método natural" ou agricultura natural [...].

Nos últimos anos têm-se observado o aumento dos casos da degradação da saúde através da alimentação que vem sendo divulgado através de pesquisas das mais variadas pelo meio científico e instituições das mais renomadas do campo da medicina, bem como através das matérias divulgadas pelos meios de comunicação.

A Fundação Mokiti Okada - FMO (2004, p. 11), sobre a alimentação descreve:

Comparadas com o passado, as condições alimentares melhoraram significativamente. Contudo, a cada ano, apesar do grande progresso da Medicina e da Nutrição, o número de pessoas que contraem câncer, doenças degenerativas, neuroses, etc., têm aumentado. Uma das causas tem sido aos aditivos alimentares, de efeito pernicioso. Mas não só eles: podemos dizer que, fundamentalmente, o vilão é o hábito alimentar antinatural, criado pela civilização científica e tecnológica moderna da supremacia materialista.

É sabido que a intensificação pela ganância ao poder econômico traçou um rumo jamais visto na história da humanidade culminado no século XXI onde as conseqüências dos novos modos de vida têm levado o homem a ser conduzido pelos atos consumistas e exagerados incentivados pelas indústrias das propagandas e publicidades cada vez mais agressivas.

Higa (1991), sobre a agricultura natural diz:

Não é nada fácil reconsiderar a Agricultura sob o seu aspecto original da criação. Mas acredito que, se analisarmos os vários problemas que a envolvem a partir de lima posição diferente do sistema técnico atualmente predominante, isto é, se formos ver por uma ótica totalmente nova, poderá ser aberto o caminho para solucionar a situação atual. Está se formando uma consciência comunitária de que será difícil solucionar os problemas fundamentais da Agricultura através da continuidade dos atuais métodos que usam abusivamente fertilizantes e defensivos químicos [...].

Segundo Okada (1953, p. 169), o princípio básico da Agricultura Natural consiste em fazer manifestar a força do solo. Até agora o homem desconhecia a verdadeira natureza do solo [...]. Tal desconhecimento levou-o a adotar o uso de adubos e acabou por colocá-lo em estado de dependência em relação a eles [...]. 
Com o objetivo expandir o conceito e prática da Agricultura Natural e colaborar para a mudança do estilo de vida alimentar para promoção da verdadeira saúde humana, um dos caminhos é através da implantação de hortas caseiras em domicílios urbanos e rurais.

A Fundação Mokiti Okada - FMO, desenvolveu e vem implantando nos estados do Brasil, o programa "Horta em casa e Vida Saudável", com objetivo de como conduzir os participantes ao encontro do espírito da Natureza, desenvolvendo o amor altruísta e a sensibilidade individual. Em outubro de 2011 a FMO instituiu a Secretaria da Agricultura Natural - SAN sediada na cidade de São Paulo.

Desde então, já foram realizadas, de novembro de 2011 a junho de 2012, diversas oficinas com a participação de 5.559 pessoas, nas regiões de todo o Brasil. Desse número, para o desenvolvimento do programa foram formados cerca de 1.500 multiplicadores voluntários que vem atuando em todo o território nacional.

O Projeto já colhe seus primeiros resultados da através da formação de multiplicadores e participação de pessoas em vários locais no Brasil, como demonstrado na tabela 04 a seguir:

Segundo a Secretaria da Agricultura Natural (2012), em algumas escolas do estado de São Paulo, o Programa Horta em Casa \& Vida Saudável tem sido apresentado, ensinando às crianças a importância de consumir alimentos mais saudáveis e produzidos por elas mesmas. O Programa ainda tem sido apresentado em alguns eventos a convites onde diversas pessoas tiveram seu primeiro contato com a Agricultura Natural, como exemplo, ao participarem das oficinas de Horta Caseira no "Abraço à Guarapiranga" (no Solo Sagrado de Guarapiranga - SP) e na "VII Mostra Ambiental de Contagem" (no SESC Contagem - MG). A tabela 04 demonstra o número de participantes das oficinas realizadas pela FMO.

Tabela 04- Número de Participantes em Oficinas (nov/2011 a jul/2012)

\begin{tabular}{|c|c|c|c|c|}
\hline Região & $\begin{array}{c}\text { № de participantes } \\
\text { em oficinas para } \\
\text { multiplicadores }\end{array}$ & $\begin{array}{c}\text { № de participantes } \\
\text { em oficinas para } \\
\text { público da FMO }\end{array}$ & $\begin{array}{c}\text { № de participantes } \\
\text { em oficinas aberta } \\
\text { para público em } \\
\text { Geal }\end{array}$ & Total \\
\hline Nordeste & 373 & 420 & 0 & 793 \\
\hline
\end{tabular}




\begin{tabular}{|c|c|c|c|c|} 
Norte & 250 & 210 & 0 & 460 \\
\hline Centro Oeste & 885 & 232 & 40 & 1157 \\
\hline Sul & 27 & 21 & 0 & 48 \\
\hline Grande Rio & 79 & 0 & 0 & 79 \\
\hline Rio Capital & 508 & 399 & 17 & 924 \\
\hline SP Interior & 601 & 186 & 67 & 854 \\
\hline SP Capital & 201 & 216 & 0 & 417 \\
\hline SP Litoral & 205 & 260 & 17 & 482 \\
\hline Grande SP & 304 & 41 & 0 & 345 \\
\hline Total Geral & 3433 & 1985 & 141 & 5559 \\
\hline
\end{tabular}

Fonte: Secretaria da Agricultura Natural - SAN - Fundação Mokiti Okada - Julho/2012

Vários resultados estão sendo colhidos e formatados para divulgação advindos das oficinas da horta em casa, como exemplo, apresentamos a seguir o relato da Sra. Luzimar Alves de Morais, publicado na Coletânea de Experiências da Agricultura e Alimentação Natural, IMMB (2012). A Sra. Luzimar é Administradora de Empresas, residente no Rio de Janeiro onde relatou após participar em uma das oficinas em Junho/2012, que até o dia da realização da oficina, há cinco anos vinha tendo problema da saúde através da descamação dos pés, rachaduras profundas e sangramento diário nas feridas. $O$ dermatologista não vinha encontrando solução precisa após os diagnósticos.A Sra. Luzimar decidiu colocar em prática os conhecimentos da oficina da horta em casa e começou a sua mudança de hábito alimentar com objetivo de diminuir o consumo de alimentos contaminados com adubos e agrotóxicos.Após algumas semanas praticando a alimentação saudável e interrompendo o uso de medicamentos, observou que estava melhorando a cada dia, seus pés sem odor, as feridas estavam cicatrizando e o sangramento parou. Com isso começou a andar normalmente e com sapatos fechados o que antes era impossível. Relata ainda que com a prática da horta caseira reduziu parte dos gastos financeiros com produtos advindos do cultivo de verduras e legumes e tomou consciência da importância de se respeitar a natureza, o que não acontecia antes.

Este é apenas um exemplo de como a alimentação saudavel pode mudar a vida das pessoas, nosso papel é fundamental na divulgação de pesquisas que ajudem a divulgar as formas adequadas de alimentação. 


\section{4- CONSIDERAÇÕES FINAIS}

Para se compreender o papel da alimentação na evolução humana, devemos nos lembrar de que a procura pelo alimento, seu consumo e, finalmente, como ele é usado para processos biológicos são, todos, aspectos críticos da ecologia de um organismo. A energia dinâmica entre organismos e seus ambientes, ou seja, a energia despendida comparada à energia adquirida, tem conseqüências adaptativas importantes para a sobrevivência e reprodução.

A consciência alimentar das pessoas vem se modificando paulatinamente, fazendo com que considerável número de indivíduos requeira alimentos livres de agrotóxicos, alimentos orgânicos e preocupando-se com os impactos ambientais. A agricultura orgânica se diferencia da tradicional justamente por saber utilizar adequadamente os recursos disponíveis no meio ambiente e aplicar somente artigos naturais, como adubos e sementes para o seu modo de produção. A agricultura orgânica é ainda carente de incentivos para a produção, sendo que uma das principais dificuldades desse âmbito é o poder político pouco presente entre os produtores de alimentos naturais, que acabam muitas vezes tendo a migração dos consumidores de produtos naturais para os alimentos feitos em condições convencionais, por questões de ordem econômica. Temos que fazer nossa parte, pois a produção orgânica representa um modelo de produção limpa, que necessita do respaldo de consumidores para se tornar viável.

\section{REFERENCIAS BIBLIOGRÁFICAS}

BRASIL, Agência Nacional de Vigilância Sanitária - ANVISA. PROGRAMA DE ANÁLISE DE RESÍDUOS DE AGROTÓXICOS EM ALIMENTOS (PARA) - Relatório de Atividades 2009. Brasília, junho, 2010. Disponível em: http://portal.anvisa.gov.br/wps/content/Anvisa+Portal/Anvisa/Inicio/Agrotoxicos+e+Toxicologia/Assu ntos+de+Interesse/Programa+de+Analise+de+Residuos+de+Agrotoxicos+em+Alimentos. Acesso em: 04 set.2012. 
BRASIL, Agência Nacional de Vigilância Sanitária - ANVISA. PROGRAMA DE ANÁLISE DE RESÍDUOS DE AGROTÓXICOS EM ALIMENTOS (PARA) - Relatório de Atividades 2010. Brasília, dezembro, 2011. Disponível em: http://portal.anvisa.gov.br/wps/content/Anvisa+Portal/Anvisa/Inicio/Agrotoxicos+e+Toxicologia/Assu ntos+de+Interesse/Programa+de+Analise+de+Residuos+de+Agrotoxicos+em+Alimentos. Acesso em: 04 set.2012.

BRASIL, Agência Nacional de Vigilância Sanitária - ANVISA. Brasília, setembro, 2012. Disponível em:

http://portal.anvisa.gov.br/wps/content/Anvisa+Portal/Anvisa/Inicio/Agrotoxicos+e+Toxicologia/Assu ntos+de+Interesse/Programa+de+Analise+de+Residuos+de+Agrotoxicos+em+Alimentos. Acesso em 04 set.2012.

BRASIL, Ministério da Agricultura, Pecuária e Abastecimento - MAPA. Plano Nacional de Controle de Resíduos e Contaminantes - PNCRC. Brasília, agosto, 2012.

Disponível em:

http://www.agricultura.gov.br/animal/qualidade-dos-alimentos/residuos-e-contaminantes. Acesso em: 04 set.2012.

CARNEIRO, F. et Al. Dossiê ABRASCO - Um alerta sobre os impactos dos agrotóxicos na saúde. 1a Parte, Rio de Janeiro: Abrasco, 2012.

GOMES, A., Conselho Científico-Religioso: Boletim Trimestral. Ano 1 - No. 1. São Paulo: MOA, 1990.

HIGA, Teruo. Agricultura Natural - A solução do Problema Alimentar. $2^{2}$ ed. São Paulo: Tradução MOA, 1991.

IGREJA MESSIANICA MUNDIAL DO BRASIL. Coletânea de Experiências de Fé - Agricultura e Alimentação Natural. No. 3, São Paulo: Secretaria de Expansão, 2012.

KHATOUNIAN, C. A. A Reconstrução Ecológica da Agricultura. Botucatu: Agroecológica, 2001.

LEONARD, W. R. Alimentos e Evolução Humana - Mudança alimentar foi a força básica para sofisticação física e social. Scientific American Brasil. Disponível

em:http://www2.uol.com.br/sciam/reportagens/alimentos e evolucao humana.html. Acesso em 03 set.2012.

OKADA, Mokiti. A Outra Face da Doença. $2^{\underline{a}}$ ed. São Paulo: MOA Shoji, 1986.

OKADA, F. M. Alimentação com Energia Vital: Visão de Mokiti Okada. 1ª Ed. São Paulo, Yangrafi, 2004.

PIMENTA, M. Agrotóxicos: A feira envenenada. Agosto, 2006. Disponível em:

http://planetaorganico.com.br/site/index.php/a-feira-envenenada-por-marcia-pimenta-282006/.

Acesso em 05 set.2012.

SANTOS, J.G. Indicadores de Sustentabilidade Para o Turismo: uma proposta de indicadores e critérios de análise para o monitoramento da atividade. SIMPOI, 2012. 